*Please cite Version of Record:

British Journal of Aesthetics 59(4): 449-464. (2019)

DOI 10.1093/aesthj/ayz033 *

\title{
Sensory Force, Sublime Impact, and Beautiful Form
}

\author{
Eli I. Lichtenstein
}

\begin{abstract}
Can a basic sensory property like a bare color or tone be beautiful? Some, like Kant, say no. But Heidegger suggests, plausibly, that colors 'glow' and tones 'sing' in artworks. These claims can be productively synthesized: 'glowing' colors (etc.) are not beautiful; but they are sensory forces - not mere 'matter', contra Kant - with real aesthetic impact. To the extent that it inheres in sensible properties, beauty is plausibly restricted to structures of sensory force. Kant correspondingly misrepresents the relation of beautiful wholes to their parts. Beautiful form is not extrinsic to sensory force. Sensible beauty is just the holistic impact of agonistically-interacting sensory forces. When sensory forces interact hierarchically, their collective impact is closer to the sublime, in quality if not degree. The simplest sensory experience of sublimity is just the impact of radically intensified sensory forces, similar in kind if not degree to the individual 'singing' tones in a beautiful melody.
\end{abstract}

1.

Can a basic sensory property like a bare color or tone be beautiful? Some say no. For instance, Kant claims that experiences of beauty are always elicited by the spatiotemporal "shape or play" of sensations like colors or tones - by sensible 'form', as he says, never by the sensory 'matter' it comprises. ${ }^{1}$ Kant's brand of aesthetic formalism hence involves a structuralist analysis of beauty. This is somewhat atypical: aesthetic or artistic 'formalism' now more often refers to the view that only properties available via sensory perception, or things' appearances, bear directly on judgments of aesthetic or artistic value. Colors and tones are 'formal' features, in this sense. Thus 'form' is often opposed to cognitive or expressive 'content', not sensory matter. ${ }^{2}$

The stark contrast that Kant draws between beautiful form and sensory matter may seem implausible. Indeed, Heidegger suggests that it is precisely in art that "metals come to flitter and shimmer, colors to glow, tones to sing, the word to speak." ${ }^{3}$ Likewise, the stone of the Greek

1 Kritik der Urteilskraft (KU) 5:224-5. I use the Guyer and Matthews translation (Kant 2000). Kant qualifies that the 'purity' of a 'simple color' can be taken as a formal property ('uniformity'); hence, he allows that a 'simple color' can be beautiful insofar as its simplicity is an aspect of its form.

2 For instances of this more standard 'formalism', see e.g. Bell 1913 (but see note 14 below); Fry 1918; Hanslick 1986; Kivy 1990 and 1993. Cf. Walton 1970; Binkley 1970; Ekman 1970; Danto 1981, 1986, 1997; and Carroll 2001. For formalism about nature, not art, see e.g. Zangwill 2001, 2005. Cf. Carlson 1979; Parsons 2004; Parsons and Carlson 2004. For a 'moderate' formalism, see Zangwill 2001, ch. 4-8. See also Thomson-Jones' (2005) argument that aesthetic cognitivism is compatible with the 'inseparability' of artistic form and content.

3 Heidegger 1971, 46. 
temple first "comes to bear and rest and so first becomes rock" in its incorporation into the 'temple-work'. Hence, the rock in the temple is set forth-not just used up, as it is in fashioning a mere stone tool. "To be sure," Heidegger allows, "the painter also uses pigment, but in such a way that color is not used up but rather only now comes to shine forth." ${ }^{6}$ In Heidegger's theory of art, then, 'colors' and 'tones' take on a very different quality than they do for Kant. Contra Kant, moreover, it is hard to deny the intuitive plausibility of Heidegger's descriptions. Sensuous 'material' is evidently elevated to newfound dignity and splendor through its incorporation into great artworks. Thus, Kant's structuralist analysis of beauty may seem to be radically misguided.

But, I argue below, a loosely Kantian association of beauty with structural form can be productively synthesized with a broadly Heideggerian vision of 'glowing' colors and 'singing' tones as loci of inherent aesthetic value. The resultant view depends upon clearly distinguishing beauty from other kinds of aesthetic value, and is surprisingly plausible: Pure 'glowing' colors and 'singing' tones are never beautiful, in themselves. But they are sensory forces-not mere 'matter'-with real aesthetic impact. The simplest sensory experience of sublimity is just the overwhelming impact of radically intensified sensory forces, similar in kind if not degree to the individual 'singing' tones in a beautiful melody. In turn, sensible beauty is plausibly restricted to structures of sensory force. More specifically, I argue that purely sensible beauty is just the holistic impact of agonistic interactions among sensory forces. By 'agon', I mean tension among well-matched forces. Real friendship and real enmity are both forms of agon, for instance, as is healthy romantic love. I provide artistic examples of agon, below. And I show how my emphasis on aesthetic agon is related to Kant's theory of 'free play', yet without relying on Kant's traditionalistic theory of humans as essentially 'sensuous-rational' beings.

Agon among sensory forces is to be contrasted against aesthetic hierarchy, or dynamic interaction between loci of relatively unequal aesthetic impact. For instance, consider the subsumption of some musical elements under others, as mere accompaniment to a dominant melody or lead voice. I argue that hierarchically-interacting sensory forces elicit experiences that are more similar - in quality if not necessarily in degree - to the sublime impact of radically intensified but 'formless' sensory force than to the experience of beauty.

Hence, I propose a novel model of the relationship between beauty and sublimity. Note

4 Heidegger 1971, 46.

5 Heidegger uses the term 'equipment' [das Zeug]. For its broader context in his thought, see Dreyfus 1992.

6 Heidegger 1971, 47. 
that I am not denying the potential relevance of affective states or 'expressive' content to aesthetic experience. Genuinely aesthetic experiences plausibly vary in the degree to which they involve less purely 'sensory' modes of activity, whether this be imaginative, affective, or narrowly cognitive. For instance, the sound of nails scraping on a chalkboard may be distasteful apart from any imaginative associations it elicits. Correspondingly, the saturated red or orange of the sky during a sunset may be aesthetically impactful apart from any 'ideas' it invokes - even if some experiences of the sublime do involve the "sensible rendering of moral ideas," as Kant claims. ${ }^{7}$ Thus I simply aim to describe a purely sensory aspect of aesthetic experience. My basic goal is to elaborate, historically contextualize, and demonstrate the explanatory power of this novel account of the relationship between beauty and sublimity, mediated by sensory force.

\section{2.}

It will be helpful to situate my view in relation to more standard varieties of aesthetic or artistic 'formalism'. But to that end, in this section I will first briefly elaborate some of my central claims about sensory force, vis-à-vis beauty and sublimity, and provide concrete artistic examples that I take to provide intuitive phenomenological motivation for these claims. In the next section, I will then contrast my account against more standard kinds of 'formalism'. In so doing, I will also explain how several different senses of the term 'form' are interrelated. Finally, I will elaborate the relationship between my account and the deeper systematic motivation for Kant's formalism about beauty, which concerns his fairly traditionalistic theory of human nature.

At present, I will proceed by way of response to a basic question: If my appeal to 'aesthetic impact' is specifically intended to encompass the effect of sensory forces like Heidegger's 'glowing' colors and 'singing' tones, then why do I not just allow that aesthetic impact is a kind of beauty? First, note that beauty is not the only aesthetic value. Hence, even if a thing like a 'singing' tone clearly has aesthetic value, this does not provide evidence that it is beautiful. Likewise, if one is told that a given thing is an animal, this does not provide evidence that it is a human, rather than a dog or a lizard. Beauty is just one species of aesthetic value.

Second, consider that although 'glowing' colors (etc.) can evidently be aestheticallysignificant aspects of beautiful things, it does not follow that these sensory forces are beautiful in themselves. For instance, the chemical bonds between individual molecules in a liquid are

$7 \quad K U$ 5:356. See also $K U$ 5:257. 
directly relevant to the liquidity of the ensemble; but none of the individual molecules is liquid, in itself. Liquidity is thus an emergent property of the collection of molecules, as some metaphysicians and philosophers of science put it. ${ }^{8}$ Likewise, I claim that purely sensible beauty is an emergent property of an ensemble of sensory forces, grounded in their interactions with one another. Here it is helpful to compare John Dewey's account of "the intimacy of the relations that hold the parts together," which he calls "[t]he characteristic of artistic design": "[a] work of art is poor in the degree in which [these relations] exist in separation, as in a novel wherein plot - the design - is felt to be superimposed upon incidents and characters instead of being their dynamic relations to one another." This is how I envision the relation between sensory force and beauty: a purely sensible beautiful form just is a dynamic interaction among the sensory forces it comprises. Indeed, this is one reason why these constitutive parts are aptly termed sensory forces: 'glowing' colors and 'singing' tones are essentially characterized both by their power to impact perceiving subjects, and by their power to interact with other sensory forces.

One might wonder whether this account can accommodate cases of beauty that apparently inhere in sensible forms to the exclusion of any sensory 'matter' or 'force' they comprise - filigree patterns in art, for instance, or the kinds of graceful "lines aimlessly intertwined in each other under the name of foliage" that Kant saw as paradigms of natural beauty. ${ }^{10}$ However, even the most delicate lines or finest gossamer threads must have breadth in order to be truly sensible or imaginatively 'pictured', and thus (qua beautiful) must contain some sensory 'matter' (or force) beyond pure 'form'. To be sure, beautiful forms may have impact greater than the impact of their disaggregated parts. But this is consistent with the existence and real aesthetic impact of these parts, and with my claim that the impact of a beautiful form is just the impact of interaction among the sensory forces it comprises. Some beautiful forms plausibly elicit experiences as of immateriality or 'pure form'. But this is consistent with such 'pure forms' in fact having aesthetic impact only by virtue of interactions among constitutive loci of sensory force, such as the blackness of a delicate line drawn on white paper. Here it is helpful to consider a sonic analogue: 'pure rhythm', like a temporal pattern of snare-drum pulses (or finger-taps, etc.) so brief and amelodic as to seem totally beyond the domain of 'tone' as a locus of sonic force. Even if such a pure rhythmic pattern can be beautiful, though, this might just show that it is constituted

8 On emergence, see e.g. Kim 1999; cf. Shoemaker 2002.

9 Dewey 1934/1980, 121.

10 KU 5:207. 
by interactions among fairly indeterminate sensory forces, like sound as opposed to silence. ${ }^{11}$ In this light, the apparent 'immateriality' of some delicate visual lines might be analyzed in terms of interactions among fairly indeterminate loci of visual force, like one color insofar as it stands in spatial relation to itself (as a visible line) or contrasts with another ('background') color. Finally, it is no threat to my account if some or all experiences of beauty also involve conceptualizing truly imperceptible forms, like breadthless mathematical lines, as cognitive 'content'. For again, I simply aim to describe a purely sensory aspect of aesthetic experience.

Third, artworks involving nothing but 'glowing colors', 'clanging tones', and so forth, are not beautiful. Note that one need not necessarily agree that a particular work is or is not beautiful, in order to find this abstract point plausible. For instance, consider Olafur Eliasson's Your rainbow panorama (2006-2011), a large, elevated circular track of about 50 meters in diameter, encased on all sides in intensely color-saturated monochromatic glass, which gradually changes in hue along the circumference - such that a viewer walking around the track passes first through a region in which everything appears intensely red (e.g.), then orange, then yellow, green, etc. The view from any given point inside this structure is surreally monochromatic, imbuing the world with an aesthetically-forceful 'glow' if ever there was one. And yet the world thus viewed, as a formless sea of a singular 'glowing color', is plausibly less beautiful than sublime. Or, more precisely, perhaps it is simply aesthetically impactful — an intensified version of the experience of being impacted by a 'glowing' color in a painting, for instance, even if it does not rise to the level of the sublime. Likewise, imagine a musical work consisting in a single prolonged blast on a giant horn. Such a pure 'singing' (or 'blaring') tone may certainly be aesthetically striking, rousing, or awesome. But I contend that it would nevertheless be far from plausibly beautiful. So too, finally, consider that around sunset refracted reddish or purple hues in the sky sometimes induce a similar color in vast swaths of the landscape. But the resulting experience of an all-encompassing color or hue - aptly termed a 'formless' sensory force - is more plausibly related to feelings of the sublime than to beauty.

Respecting this intuitive phenomenological distinction, therefore, I am referring to the effect of 'glowing' colors, 'singing' tones, etc. as the feeling of aesthetic impact. This in turn plausibly becomes a feeling of the overwhelming aesthetic impact of the sublime, when it is radically intensified. (There may well be other grounds of the sublime besides this one.) And

11 Thus, a given rhythmic form might even be 'played' in the medium of silence as opposed to sound-for instance, as a pattern of cessations or interruptions within an otherwise sustained auditory tone. 
both must be distinguished from the distinctive feeling elicited by beauty, although I claim that purely sensory beauty is an emergent property of dynamic interactions among sensory forces. Thus, on my view, the simplest purely sensory experience of the sublime is just an intensified version of the same kind of aesthetic impact that is elicited by the individual 'glowing' colors or 'singing' tones in a beautiful painting or song.

Sublimity is not essentially related to structure, in the way that beauty is. The sublimity of a 'formless' field of intense light or sound evidences this point. In this context, it also helps to observe the phenomenological relation between feelings of the sublime and the feeling elicited by musical drones, or by certain kinds of abstract art that privilege 'glowing' colors and impenetrably-simple geometrical shapes-i.e. shapes that do not impact us as internally-complex forms. The latter two phenomena are arguably exemplified in some Abstract Expressionist paintings, like Mark Rothko's No. 14, 1960, as well as in Minimalist sculptures like Tony Smith's Die (1962). Note that some internally-complex forms may (as such) elicit true experiences of sublimity - e.g. consider looking out at endless perfectly-straight rows of plants on a huge industrial farm - even if sublimity is not essentially related to internal structure. The intuitive contrast between the sublime impact of a 'formless' field of intense light and the sublime impact of endless perfectly-straight rows of plants is arguably related to the phenomenological plausibility of Kant's distinction between the 'dynamical' and 'mathematical' sublime. ${ }^{12}$ However, whereas Kant suggests that both kinds of sublimity involve a feeling of reason's superiority over sense, ${ }^{13}$ I claim only that the sensory aspect of sublimity involves a feeling of overwhelming aesthetic impact - whether it be the impact of a radically-intensified but 'formless' sensory force, or that of certain structures of sensory force. (Here one might distinguish two kinds of 'formlessness': the expansiveness of things like the ocean, and the non-extensive quality of pure sensory force. The former involves structure even if the latter does not, e.g. insofar as the apparent expanse of some color-fields involves intuitable spatial relations of a color to itself.)

Finally, recall that not all structural configurations of sensory force are beautiful, on my view. Rather, sensible beauty is grounded in agonistic interaction among sensory forces-i.e., in tension between well-matched sensory forces, which we experience as beautiful form. This is by

12 For Kant, nature is dynamically sublime insofar as it manifests as a "power" that "arous[es] fear," yet which "has no dominion over us" (KU 5: 260). By contrast, we experience the mathematical sublime in attempting to intuitively comprehend ( $K U 5: 251-2)$ magnitudes so vast that we cannot in fact fully imagine them (KU 5:255). I thank an anonymous referee for pressing me to elaborate this point of connection.

$13 K U$ 5:257. 
contrast to hierarchical interactions among unequal sensory forces, which elicit feelings of what I will call aesthetic order. A set of musical examples will help to illustrate this point.

Harmony vs. Counterpoint: Music structured by contrapuntal motion has strongly independent, individually self-standing melodic lines that nevertheless seem to 'play' back and forth off of one another to create a coherent aesthetic effect. Canonically, for example, consider the relationship between lower and higher voices in Bach's Art of Fugue. Similarly, one may think of the dynamic tension between drums, bass, piano, and 'lead' horn instrument in much post-bop jazz, as in Miles Davis's 'Agitation' (1965). This style of music is of course heavily driven by improvisational soloing, which hence naturally situates the solo voice as a focal point for collective melodic and rhythmic development. But in the best small-combo jazz, the soloist nevertheless remains continually and intensely responsive to the rhythmic, melodic, and harmonic figurations of his fellow musicians, who are themselves constantly improvising and stepping alternately to the fore and to the back of the collective performance even within the context of their 'accompanying' role. In this sense, then, the internal dynamic tension of an elite jazz combo can be meaningfully subsumed along with the contrapuntal motion of classical fugues under a broader category of counterpoint. And counterpoint thus construed is related to agonistic form: the interacting voices are relatively equal in power of aesthetic impact.

By contrast, harmony functions as a locus of aesthetic order insofar as it involves the radical subsumption of some musical elements under others in the mode of genuine accompaniment to a sonically-dominant melody or lead voice. Here consider the 'harmonious' relationship between dominant lead voice and rhythmic accompaniment during John Coltrane's initial melodic articulation in 'Naima', a ballad dedicated to his first wife. Notably, the fact that small-combo jazz performance is often driven largely by collective improvisation over fixed chord progressions, as opposed to pre-planned performance of melodic themes, helps to explain why the relation between solo instrument and rhythm section in this music is more 'contrapuntal' than is the relation between solo and accompaniment in many classical compositional forms.

Yet 'harmony' is also intuitively related, not to hierarchy or unilateral determination, but rather precisely to balance, equality, and symmetry. In the musical context, harmony is therefore opposed not only to counterpoint, but also to dissonance and to sonic imbalance. Furthermore, musical harmony is naively thought to be beautiful, by contrast to 'ugly' sonic dissonance. This apparently stands in tension with the association I have drawn above, between harmony and 
hierarchical aesthetic order, as opposed to beautiful agonistic form. But this tension is merely apparent, grounded in equivocation between harmony as opposed to counterpoint, and harmony as opposed to dissonance. Harmony as opposed to dissonance does indeed involve a mode of beautiful agonistic form. Yet dissonance, too, can be a locus of beautiful agonistic form. Of course, uncontrolled dissonance is not beautiful. But when properly deployed, dissonant harmonic relations may certainly constitute agonistic forms. Indeed, my notion of an agonistic form, or system of agonistic relations among forces that itself functions as a collective locus of force, captures the aesthetic unity of harmony and dissonance. Both harmony and dissonance, insofar as they are beautiful, involve systems of dynamic tension among well-matched-sensory forces, which collectively function as coherent loci of aesthetic impact.

This account also helps to explain why the aesthetic impact of hierarchically-interacting loci of sensory force is qualitatively (not necessarily quantitatively) similar to the overwhelming impact of the sublime. Both essentially involve aesthetic hierarchy. In experiences of sublimity grounded in radically-intensified but 'formless' sensory force, a perceiving subject firstpersonally experiences his own hierarchical determination by sensory force. In the case of hierarchy within a given aesthetic object (e.g. the subordination of rhythmic accompaniment to a lead melodic voice), a subject instead third-personally apprehends hierarchical determination of sensory force by sensory force. In either case, then, the subject apprehends sensory force in the mode of asymmetrical impact. This is not to say that experiences of the sublime are the same as experiences of hierarchical aesthetic order within a given artwork or natural phenomenon. But it does help to explain their phenomenological proximity.

\section{3.}

With this intuitive motivation in tow, it now bears further elaborating that the broadly Kantian notion of form as relational structure, which I emphasize, is not the only salient notion of form in aesthetics. ${ }^{14}$ The English form shares a common set of denotations with the Latin forma and the Greek morphe and eidos: all denote (1) appearance, especially in the sense of outward or sensible appearance - hence, the traditional association between form and aesthetics

14 Note that Clive Bell defines 'Significant Form' as "[t]hese relations and combinations of lines and colours, these aesthetically moving forms" (Bell 1913, 8). This suggests an opposition between form and sensory matter, not 'content'. However, Bell's appeal to 'lines' (qua spatiotemporal structures) complicates this analysis. Both the 'form-matter' and 'form-content' distinctions are plausibly salient, for Bell. This combination of distinctions is typical of many post-Kantian theories of art emphasizing 'expressive form'-e.g. see Langer 1953, 1957. 
construed as episteme aisthetike or the science of aesthesis (perception, and especially sensory perception); ${ }^{15}$ (2) shape, configuration, or structure; (3) kind or type; and (4) shapeliness or beauty itself. ${ }^{16}$ I am placing primary emphasis on (2), and secondary emphasis on (1): I claim that purely sensible beauty only inheres in intuitable relational structure among sensory forces. ${ }^{17}$

This is atypical. More commonly, again, 'formalists' are those who claim that beauty-or, more broadly, aesthetic or artistic value - is solely a property of things' appearance, and especially their sensible characteristics or style. For instance, form, in this sense, encompasses both the color and shape of a sculpture; the pacing and cinematographic technique displayed in a given film; the use of ekphrasis or specific metrical structures in a given lyric poem; and the stream-of-consciousness narratorial voice deployed in a given modernist novel. An aesthetic object's form, thus construed, is opposed to its content, not to its sensory matter. 'Content' here typically includes several distinct things. First, it typically includes representational content, e.g. the fact that a given painting depicts a landscape or a Dutch aristocrat, or that a particular melodic figure resembles the cadence of human speech. Second, 'content' typically includes expressive content, e.g. that a certain dance seems to express human feeling-without necessarily depicting it. ${ }^{18}$ Third, 'content' typically includes moral content, e.g. that Leni Riefenstahl's Triumph of the Will presents a glorified and hence morally abhorrent vision of the Nazi party. Finally, 'content' typically includes truth content, e.g. that Turgenev's Fathers and Sons (1862) accurately depicts certain real features of mid-19 ${ }^{\text {th }}$-century Russian provincial society.

Further distinctions can be helpfully drawn within the broad category of artistic or aesthetic 'formalism', in this standard sense. For instance, radical formalists insist that one can legitimately consider only an artwork's form, and so not its content, when assessing its artistic or aesthetic value. By contrast, more moderate formalists that artistic or aesthetic evaluation may properly involve consideration of both an artwork's form and its content, but still insist that the latter has artistic or aesthetic significance only in the context of evaluating the relationship between content and form. Specifically, a typical moderate formalist might insist that artistic or

15 See Baumgarten 1954, 78; Heidegger 1991, 77-8; and Adorno 2018, 18.

16 'Beauty' is given as an archaic definition of 'form' in the Collins English and Merriam-Webster Dictionaries. For the Latin and Greek, see Lewis and Short 1879; Liddell and Scott 1889, 1940, and Cunliffe 1924.

17 I elaborate the relevant sense of 'intuitable' below.

18 On expression vs. representation, see see e.g. Collingwood 1938, Wollheim 1987. For criticism, see e.g. van Gerwen 2001. 
aesthetic evaluation of a given artwork can properly include consideration of its form, but also whether this form coheres with or functions to effectively express its content. ${ }^{19}$

I am neither a radical nor a moderate 'formalist', in this standard sense. I do take beauty to depend upon sensible (or, more precisely, intuitable) appearance. Things cannot be beautiful just by virtue of their 'content', on my view. ${ }^{20}$ But I do not claim that any 'content' can sensibly appear as beautiful form. For instance, I am happy to allow that it might be impossible to produce truly beautiful artistic expressions of ethically-abhorrent or politically-heinous attitudes. Thus my view differs from standard 'formalism': my analysis of sensory aspects of aesthetic experience is entirely compatible with the possibility that 'content' might also have intrinsic bearing on aesthetic value - although if it does not, then my account clearly allows for that, too.

Although the formalist thesis that beauty inheres exclusively in sensible appearance is already highly controversial, the claim that beauty inheres exclusively in shape or configuration would likely be only still more widely contested. Form construed as shape is typically opposed not to content, in the above sense, but rather to matter. Thus, a sculpture's shape is distinguished from the clay or bronze out of which it is formed. Likewise, aesthetic matter construed as sensation, i.e. pure color, tone, scent, taste, or tactile impression, may be differentiated from aesthetic form construed as the relational structure of sensations in the representation of a given object. Kant appeals to a variant of aesthetic form in this sense. Namely, Kant views aesthetic form as the conceptually indeterminate spatiotemporal 'shape or play' of sensations in our intuitive representations of things - for reasons that I elaborate below.

Extrapolating somewhat from Kant's evidently restrictive view, one might identify aesthetic form with not only the spatiotemporal configuration of sensations, but also their 'shape' or configuration with respect to more abstract relational structures like color spaces and their analogues for non-visual sensory modalities. In a color space, for example, variable chromatic properties like shade, tint, tone, and hue can function as dimensions along which to 'locate'

19 Mary Devereaux $(1998,244)$ characterizes a closely related view that she calls 'sophisticated formalism', according to which "[a]rtistic success consists in expressing a particular message in an effective way." But the 'moderate formalism' characterized here is less restrictive: it allows that artistic success or aesthetic value can consist in the realization of purely formal-i.e. entirely 'content'-independent — aesthetic or artistic virtues.

20 Jerrold Levinson ('Beauty is Not One: The Irreducible Variety of Visual Beauty', in Elisabeth Schellekens and Peter Goldie (eds.), The Aesthetic Mind: Philosophy and Psychology (Oxford: Oxford University Press, 2011), 190-207, at 198-9) argues that "moral beauty" arises in cases where "traits of character or virtue seem visually manifest in a person's outward form." This may seem to suggest a kind of beauty that relies entirely on 'content'. But in fact Levinson's claim that moral beauty requires virtue to "seemingly manifest in a person's appearance" renders his view consistent with (this aspect of) mine: for Levinson, too, one cannot be morally beautiful just by virtue of moral 'content'. Moral beauty is thus "no guarantee" of moral worth, but only its sensible“suggestion." 
particular visual sensations, hence providing abstract metrical structures in which to conceptualize or intuitively represent aesthetically significant chromatic 'shapes' or configurations in the manifold of visual sensations elicited by a given object. Properties like the additive and subtractive relations between particular colors might also be treated as features of aesthetic form so construed as the intuitable 'shape' or configuration of sensory 'matter'. It is helpful to view this conception of intuitable form as a synthesis of Kantian and standard formalist notions of aesthetic 'form'. Like the Kantian and unlike the standard formalist, the advocate of the present view understands 'form' as shape or structure inhering in sensory 'matter', and so denies that 'material' sensory properties like bare color or tone are features of aesthetic form. But like the standard formalist and unlike the Kantian, she does not restrict her attention to spatiotemporal relations. And like both the standard formalist and the Kantian, she denies that representational, ethical, or epistemic 'content' is a legitimate component of aesthetic form. So, for instance, an advocate of the present view would deny the 'formal' relevance of any nonrelational properties of the particular visual sensations she has upon looking at a given painting - e.g. that she sees pleasing shades of blue, green, and brown, considered apart from the relations in which these colors stand to one another. But she would also distinguish from aesthetic form things like whether this sensory matter has a collective 'shape' that is somehow expressive of a particular conception of ethical virtue, whether the given painting depicts anything at all, and if so whether the things that it depicts are morally good, actually exist, or are physically possible. I wholly endorse this notion of aesthetic form, insofar as it bears on a purely sensory aspect of aesthetic experience: beauty only inheres in this kind of relational structure among loci of sensory force, on my view, even if it also depends in some way on 'content'. To be aesthetically relevant, 'content' must sensuously appear in intuitable form, in the present sense.

Finally, generalizing still further, one might insist that 'formal' features encompass not only spatiotemporal and other intuitable configurations of sensory 'matter', but also conceptualized relations among sensations, like those dismissed above as aspects of 'content'. And in this broadest notion of relational structure, one arguably recovers the notion of form as kind or type mentioned at the outset of this section. Here consider that every determinate kind or type evidently corresponds to a concept, and in turn that on the view of some theorists - saliently including Kant - a concept is essentially a rule or a law-like relational structure through which collections of discrete particulars or manifolds of sensory 'matter' can be rationally synthesized 
into objective wholes, or taken up in acts of objective judgment.

In this way, the denotation of form as kind or type can be subsumed under the ambit of a broad structural notion of form construed as relational unity, or the way that a collection of things are interrelated as parts of a whole. So understood, form has often been associated, directly or indirectly, with rationality or our capacity for objective judgment and knowledgee.g. by Kant, as we will see. By contrast, the basic purely aesthetic notion of form, as sensible appearance, is arguably rooted in the classical distinction between the beautiful (as the highest aim of perception, the domain of aesthetics), the true (as the highest aim of judgment, the domain of logic), and the good (as the highest aim of action, the domain of ethics). ${ }^{21}$ In sum, when I claim that sensible beauty inheres only in intuitable structures of sensory force, I mean to include both spatiotemporal and other singular relations (e.g. of chromatic contrast) among sensory forces. But I do not mean to include generic relations among sensory forces: I agree with Kant that we cannot prove a thing's beauty just by indicating its conceptually-determinate features.

\section{4.}

My account of sensible beauty, as grounded in agonistic interactions among sensory forces, is in certain respects related to Kant's theory of 'free play' between imagination and understanding in experiences of beautiful form. But my account does not presuppose the theory of human nature that undergirds Kant's account. To appreciate this, we must first review Kant's account of aesthetic 'disinterestedness', and then relate it to his theory of cognition.

Kant understands 'interest' as '[ $\mathrm{t}]$ he satisfaction that we combine with the representation of the existence of an object." 22 In turn, he claims that interested satisfaction is always grounded in, or else itself grounds, a desire. ${ }^{23}$ When a desire is grounded in interested satisfaction, Kant refers to the object of this desire as merely agreeable. The agreeable is that which we want more of, simply because it "gratifies" us bodily. ${ }^{24}$ Kant presents as paradigmatic agreeable things pleasant 'sensations', e.g. impressions of objects' color or tone ${ }^{25}$ - hence presumably also their taste, smell, or tactile quality. ${ }^{26}$ By contrast, when our pleasure in representing the existence of

21 See the Heidegger reference in note 15.

$22 K U$ 5:204.

23 Ibid.

24 Ibid.

$25 K U$ 5:224.

26 Here Kant's account reflects his debt to $18^{\text {th }}$-century British theorists. E.g. Shaftesbury “excludes the sensory from the realm of the aesthetic" because he identifies beauty with harmony and argues that "harmony can never 
something is grounded in our rational desire for it, Kant characterizes this thing as good. ${ }^{27}$ On Kant's view, then, disinterested pleasure is the feeling of freedom from desire in open-ended reflection upon beautiful aesthetic form: the 'free play' [freien Spiele] of our imagination and understanding. ${ }^{28}$

In turn, Kant views this 'free play' of faculties as embodying the reciprocal relationship between powers of sensible 'receptivity' (here broadly associated with imagination) and rational 'spontaneity' (here associated with understanding) that he claims grounds the possibility of "cognition in general." 29 Kant's aesthetic formalism is thus bound up with a traditionalistic theory of human nature, according to which we are sensuous-rational beings. While this theory of human nature might not seem inherently objectionable, that Kant's theory of beauty presupposes it is perhaps grounds for suspicion. For should we accept that colors and tones cannot be beautiful, just because they do not speak directly to our rational nature? (Thus, Kant was arguably unable to recognize the aesthetic value of sensory force for the same reason that he was unable to recognize the ethical significance of inclination or arational passion, not just moral principle.)

To deepen this criticism, it is helpful to note how Kant's 'formalism' is grounded in a deeper expressive theory of beauty, related to his basic vision of taste as "at bottom a faculty for the judging of the sensible rendering of moral ideas." 30 Here note, first, that Kant's notion of aesthetic form approaches the boundary of conceptual representation from the side of intuition. Like intuitive representations, judgments of beauty are singular. ${ }^{31}$ This corresponds directly to Kant's view that judgments of taste are subjectively rather than objectively grounded, or 'aesthetic' rather than 'logical', and likewise to his view that "there can[...]be no rule in accordance with which someone could be compelled to acknowledge something as beautiful." 32 Insofar as judgments of beauty are justified by appeal to the feeling of free play rather than by pointing to objective features of beautiful things, Kant believes, it is impossible to prove to

be apprehended by the senses;" correspondingly, the "objects of sense" only satisfy "lower," "material" desire (Stolnitz 196ab, 109-110). Compare Shaftesbury 2000, 321-2. On 'disinterestedness' in 18 $8^{\text {th }}$-century British aesthetics, see also Stolnitz 1961a; Rind 2002; Berleant 1986. On Kant's relationship to this British context, see White 1973; Townsend 1987; and Guyer 1993.

27 KU 5:207-209.

$28 K U 5: 217$.

$29 K U$ 5:215-217.

$30 K U$ 5:356.

$31 K U$ 5:215.

$32 K U$ 5:215-216. 
someone that a given thing is beautiful simply by describing it in generic terms. Rather, when it comes to judgments of beauty one always has to "submit the object to his own eyes" 33 in order to see whether its immediate sensory impact indeed initiates the harmonious free play of imagination and understanding. Aesthetic form, in turn, is for Kant evidently the 'form' into which the sensory 'matter' of an empirical intuition is composed. By thus dissociating aesthetic form from the raw 'matter' of sensation, Kant explicitly seeks to insulate judgments of beauty from idiosyncratic individual responses to (merely 'agreeable' or 'gratifying') sensory qualities. And by identifying aesthetic form with the relational structure of sensations, he in turn seeks to correlate judgments of beauty with the universally-accessible features of objects. Another way to appreciate this point, given traditional associations between universality and rationality, is to recognize that for Kant the representation of aesthetic form necessarily involves 'a formal determination of the unity of a manifold of [sensations]', ${ }^{34}$ and so always already involves activation of the subject's capacity for rational spontaneity, even though the beautiful 'pleases[...]without a concept'. ${ }^{35}$

In brief, this is possible (Kant claims) because he understands judgments of beauty as aesthetic reflecting judgments: to judge that a given object is beautiful is to claim that the spatiotemporal form of a corresponding intuitive representation of the object is 'subjectively purposive', or "purposive for the reflecting power of judgment by itself, i.e., in the mere intuition without any concept." ${ }^{\prime 6}$ Kant thus understands the feeling of 'free play' between imagination and understanding to constitute a special kind of judgment, which aims not at subsuming a given beautiful intuitive form under the concept of a determinate kind of object of possible experience, but rather at relating this beautiful form to the concept of the universal subjective conditions of possibility of objective (reflecting) judgment itself. So, whereas in the standard 'objective' use of reflecting judgment a given empirical intuition might be subsumed under the concept [dog], in judgments of beauty a given empirical intuition is subsumed under the concept [subjective purposiveness for the objective use of reflecting judgment in general].

Kant thus claims that finding something beautiful essentially involves 'holding it together' (i.e. synthesizing the manifold of sensations it elicits) using a purely intuitive form corresponding to the concept of a generic rational subject who perceives objects in space and 
time, as opposed to the concept of a specific kind of object. In other words, Kant roughly claims that objects are beautiful insofar as they represent the generic 'sensuous-rational' structure of human cognition in empirical intuition. Spatiotemporal 'form' is suited to perform this representational role because (Kant thinks) it directly involves both our faculties of sensory 'receptivity' and rational 'spontaneity', whereas raw sensory 'matter' involves only the sensuous aspect of our nature. This is why Kant is a formalist about beauty.

5.

However, broadly Kantian formalism about beauty need not be tied in this way to a traditionalistic theory of humans as essentially sensuous-rational beings. One way to decouple these positions is to acknowledge that what Kant degrades as mere sensory 'matter' can in fact be a locus of aesthetic value in its own right - while insisting that it is never beautiful, per se, apart from its structural form. This is where sensory force and aesthetic agon are useful notions.

On my view, intuitable form is not essentially linked to beauty because it mediates between 'rational spontaneity' and 'sensory receptivity', as spatiotemporal form does for Kant. Rather, intuitable form is the proper focal point for several other reasons: (i) It matches the phenomenological data, in the sense that 'formless' sensory force just does not seem to be beautiful-here recall section 2 above. (ii) Emphasis on intuitable form still allows for the kind of 'freedom from concepts' that is an attractive feature of Kant's account. Like Kant, that is, I claim that valid judgments of beauty are justified by appeal to a feeling, not by pointing to objective features of beautiful things. ${ }^{37}$ And one crucial aspect of this feeling, at least, is aesthetic agon: the impact of agonistic interactions among loci of sensory force, like contrapuntallyinteracting melodies. Kant is right that in judgments of beauty one always has to "submit the object to his own eyes", ${ }^{38}$ and my account retains this feature. (iii) My account is more flexible than Kant's, however, insofar as I do not restrict intuitable form to spatiotemporal relations, but also allow that beautiful form's 'structure' might consist in purely intuitive relations like those of dynamic contrast between instruments.

My emphasis on agonistic interactions, specifically, adds several further advantages: (iv) Again, this matches the phenomenological data: things like harmony and dissonance can both be beautiful; but extreme imbalance, even insofar as it is aesthetically effective-e.g. an

37 Compare also Schopenhauer 1966, 409.

$38 K U$ 5:216. 
overwhelming solo voice that overpowers all accompanying parts in an attractive way-tends rather towards the sublime or even just the intensely impactful, rather than towards beauty. One natural explanation of this is that beauty is tied to tension among sensory forces with similar intensities. (v) Pointing to agonistic interactions within beautiful things provides an objective ground for the distinctively open-ended character of experiences of beauty. As Alexander Nehamas observes in a broadly Kantian spirit, beauty apparently concerns "attractions that exceed our ability to articulate them in terms that we already understand, and promise to reveal to us something never seen before." 39 It is arguably this "promise of more," of more valuable experience to come, that makes something beautiful. ${ }^{40}$ And I claim that dynamic tension among well-matched sensory forces would naturally elicit a purely sensory feeling of open-endedness, in this vein.

Does this mean that sublimity does not elicit this same 'promise of more', on my account? Here we must distinguish two kinds of open-endedness. First, agonistic interaction elicits a kind of open-endedness: unresolvable tension among well-matched forces. In this respect, 'formless' sublime force does not elicit feelings of open-endedness. Second, however, the impact of all sensory force involves another kind of open-endedness related to the freedom from concepts described above. Beauty and sublimity alike involve this second experience of open-endedness. Here my view also bears meaningful resemblance to Heidegger's fuller account of things like 'glowing' colors. Let me briefly explain:

According to Heidegger, the totality of 'glowing' colors, 'singing' tones, and so on-i.e. the sensuous materiality of the artwork as "[t]hat into which the work sets itself back and which it causes to come forth in this setting back of itself' - is the 'earth'. ${ }^{41}$ The earth is 'set forth' in the stone of the temple or the sculpture of the god within, as this stone "presses downward and manifests its heaviness." We can precisely determine the weight of the stone by placing it on a balance, Heidegger claims, but in so doing "the weight's burden has escaped us." Indeed, according to Heidegger we can only "lay hold of the stone's heaviness" in the work of art, where this heaviness yet "remains undisclosed and unexplained." 42 Thus on Heidegger's view the "selfsecluding" earth is 'set forth' precisely insofar as the work "sets itself back into" its poeticallynot-scientifically-apprehended material aspect. In short, 'earth' is the way that reality resists

39 Nehamas 2007, 86.

40 Nehamas 2007, 76. Nehamas considers 'beauty' the "collective name" of "the values of aesthetics" (ibid. 86).

41 Heidegger 1971, 46.

42 Heidegger 1971, 46-7. 
incorporation into coherent 'worlds' of human intelligibility or meaning. I do not endorse all aspects of Heidegger's account (which is too complex to explain further here). ${ }^{43}$ But in a loosely Heideggerian spirit, I claim that all sensory forces elicit experiences as of butting up against something real that cannot be fully captured in acts of objective judgment. And, in this sense, every sensory force evokes a 'promise of more'. This suggests a helpful way to view the contrast between Kantian sensory matter and my notion of sensory force: Kantian sensory matter is the sensuous aspect of reality insofar as it can be determined by our power of rational spontaneity, whether in objective cognition or in aesthetic reflecting judgment; whereas sensory force is the sensuous aspect of reality precisely insofar as it resists our power of reason and exerts power in its own right. Any cognitive activity involved in aesthetic experience may thus be the effect of 'sense' acting on 'reason', rather than vice versa.

\section{6.}

Kant is plausibly right that colors and tones are never beautiful. But contra Kant, they can be sensory forces with real aesthetic impact-like Heidegger's 'glowing' colors and 'singing' tones. Purely sensible beauty is the impact of agonistically-interacting sensory forces.

Beauty does not inhere in the spatiotemporal 'form' of sensory 'matter' because of its distinctive mediating role between sensible receptivity and rational spontaneity, as Kant claims. But a broadly Kantian structuralist analysis of beauty can be decoupled from the theory of 'rational-sensuous' human nature that undergirds Kant's account. The feeling of internal tension that Kant characterizes in terms of 'free play' between imagination and understanding is in fact often just an experience of agonistically-interacting sensory forces.

Sensory force has aesthetic impact. When sensory forces interact agonistically, they have holistic impact as beautiful form. When sensory force is radically intensified, it becomes sublime. When sensory forces interact hierarchically, their collective impact is close to sublime, in quality if not degree. The simplest sensory experience of the sublime is just the overwhelming impact of radically intensified sensory force, essentially similar in kind (not degree) to the individual 'glowing' colors or 'singing' tones in a beautiful painting or melody. The relationship between beauty and sublimity is mediated by an elemental category of sensory force. ${ }^{44}$

43 For further explication, see Thomson 2011; Young 2001.

44 I am grateful to Daniel Herwitz for invaluable feedback on earlier drafts. I am also grateful to Pavel Godfrey for helpful discussions of Heidegger, and to an anonymous referee at $B J A$ for helpful suggestions and questions. 


\section{WORKS CITED}

Adorno, Theodor W. (2018). Aesthetics: 1958/59. Translated by Wieland Hoband. Polity Press. Baumgarten, Alexander Gottlieb (1954). Reflections on Poetry. Translated by Karl Aschenbrenner and William B. Holther. Berkeley: University of California Press.

Bell, C. (1913). Art. New York: Frederick A. Stokes.

Berleant, Arnold (1986). The Historicity of Aesthetics - I. British Journal of Aesthetics 26(2), 101-111.

Binkley, T., 1970, "Piece: Contra Aesthetics," The Journal of Aesthetics and Art Criticism, 35: 265-277.

Carlson, A., 1979, "Formal Qualities in the Natural Environment," Journal of Aesthetic Education, 13: 99-114.

Carroll, N. (2001). Beyond Aesthetics, Cambridge: Cambridge University Press.

Collingwood, R. G. (1938). The Principles of Art. London: Oxford University Press.

Cunliffe, R. J. (1924). A Lexicon of the Homeric Dialect. London: Blackie and Son Limited.

Danto, A.C. (1981). The Transfiguration of the Commonplace, Cambridge, Mass.: Harvard University Press.

Danto, A.C. (1986). The Philosophical Disenfranchisement of Art, New York: Columbia University Press.

Danto, A.C. (1997). After the End of Art: Contemporary Art and the Pale of History, Princeton: Princeton University Press.

Devereaux, Mary (1998). "Beauty and Evil: The Case of Leni Riefenstahl's 'Triumph of the Will'." In Jerrold Levinson (ed.), Aesthetics and Ethics. Cambridge University Press. pp. $227-256$.

Dewey, John, 1934 (1980). Art as Experience. New York: Perigree.

Dreyfus, Hubert L. (1992). "Heidegger's History of the Being of Equipment." In Hubert L. Dreyfus and Harrison Hall (Eds.), Heidegger: A Critical Reader (Cambridge, MA: Blackwell), 173-185.

Ekman, Rosalind (1970). 'The Paradoxes of Formalism.' British Journal of Aesthetics 4(1): 350-358.

Fry, Roger (1918). Transformations. London: Chatto \& Windus.

Guyer, Paul (1993). The dialectic of disinterestedness: II. Kant and Schiller on interest in disinterestedness. In Kant and the Experience of Freedom: Essays on Aesthetics and Morality (94-130). Cambridge University Press.

Hanslick, E., 1986, On the Musically Beautiful, G. Payzant (trans.), Indianapolis: Hackett.

Heidegger, M. (1971). "On the Origin of the Work of Art." In Poetry, Language, Thought (Albert Hofstadter, Trans.) (15-87). New York: Harper \& Row.

Heidegger, Martin (1991). Nietzsche: Volumes One and Two, The Will to Power as Art \& The Eternal Recurrence of the Same. Translated by David Farrell Krell. San Francisco: Harper Collins. 
Kant, Immanuel (1998). The Critique of Pure Reason. Translated by Paul Guyer and Allen W. Wood. Cambridge: Cambridge University Press.

Kant, Immanuel (2000). Critique of the Power of Judgment. Translated by Paul Guyer and Eric Matthews. Cambridge: Cambridge University Press.

Kim, Jaegwon (1999). "Making Sense of Emergence," Philosophical Studies, 95: 3-36.

Kivy, Peter (1990). Music Alone: Philosophical Reflections on the Purely Musical Experience. Cornell Univeristy Press.

Kivy, Peter (1993). The Fine Art of Repetition: Essays in the Philosophy of Music. Cambridge University Press.

Langer, Susanne K. (1953). Feeling and Form: A Theory of Art. New York: Charles Scribner's Sons.

Langer, Susanne K. (1957). "Expressiveness.” In Problems of Art: Ten Philosophical Lectures (New York: Charles Scribner's Sons), 1326.

Levinson, Jerrold (2011). "Beauty is Not One: The Irreducible Variety of Visual Beauty." In Elisabeth Schellekens and Peter Goldie (Eds.), The Aesthetic Mind: Philosophy and Psychology (Oxford: Oxford University Press), 190-207.

Lewis, C. T., \& Short, C. (1879). A Latin Dictionary Founded on Andrews' Edition of Freund's Latin Dictionary. Revised, Enlarged and in Great Part Rewritten by CT Lewis and Charles Short. Oxford: Clarendon Press.

Liddell, H. G., \& Scott, R. (1896). An intermediate Greek-English lexicon: founded upon the seventh edition of Liddell and Scott's Greek-English lexicon. Harper \& Brothers.

Nehamas, Alexander (2007). Only a Promise of Happiness: The Place of Beauty in a World of Art. Princeton Universty Press.

Parsons, Glenn (2004). 'Natural Functions and the Aesthetic Appreciation of Inorganic Nature.' British Journal of Aesthetics 44(1): 44-56.

Parsons, Glenn, and Carlson, Allen (2004). 'New Formalism and the Aesthetic Appreciation of Nature.' The Journal of Aesthetics and Art Criticism 62(4): 363-376.

Rind, Miles (2002). "The Concept of Disinterestedness in Eighteenth-Century British Aesthetics." Journal of the History of Philosophy 40(1): 67-87.

Schopenhauer, Arthur (1966). The World as Will and Representation, v. II. Translated by E. J. F. Payne. Dover.

Shaftesbury, Anthony Ashley Cooper (2000). Characteristics of Men, Man, Manners, Opinions, Times. Edited by Lawrence E. Klein. Cambridge: Cambridge University Press.

Shoemaker, Sydney (2002). "Kim on Emergence," Philosophical Studies, 108: 53-63.

Stolnitz, Jerome (1961a). "On the Origins of 'Aesthetic Disinterestedness."” The Journal of Aesthetics and Art Criticism 20(2): 131-143.

Stolnitz, Jerome (1961b). "On the Significance of Lord Shaftesbury in Modern Aesthetic Theory." The Philosophical Quarterly 11(43): 97-113.

Thomson, Iain D. (2011). Heidegger, Art, and Postmodernity. Cambridge University Press. Thomson-Jones, Katherine (2005). 'Inseparable Insight: Reconciling Cognitivism and Formalism in Aesthetics.' The Journal of Aesthetics and Art Criticism 63(4), 375-384.

Townsend, Dabney (1987). "From Shaftesbury to Kant: The Development of the Concept of 
Aesthetic Experience." Journal of the History of Ideas 48(2):287-305.

Van Cleve, James (1990). "Mind-Dust or Magic? Panpsychism Versus

Emergence," Philosophical Perspectives, 4: 215-226.

van Gerwen, Rob (Ed.) (2001). Richard Wollheim on the Art of Painting: Art as Representation and Expression. Cambridge University Press.

Walton, Kendall L. (1970). Categories of art. Philosophical Review 79 (3):334-367.

White, David A. (1973). "The Metaphysics of Disinterestedness: Shaftesbury and Kant." The Journal of Aesthetics and Art Criticism 32(2): 239-248.

Wollheim, Richard (1987). Painting as an Art. Princeton: Princeton University Press.

Young, Julian (2001). Heidegger's Philosophy of Art. Cambridge University Press.

Zangwill, Nick (2001a). The Metaphysics of Beauty. Ithaca, NY: Cornell University Press.

Zangwill, N. (2001b). Formal Natural Beauty. Proceedings of the Aristotelian Society 101(1): 109-224.

Zangwill, Nick (2005). 'In Defence of Extreme Formalism about Inorganic Nature: Reply to Parsons.' British Journal of Aesthetics 45(2): 185-191. 